\title{
Comparing the impact of authentic leadership on Italian and UK police officers' discretionary power, well-being and commitment
}

\begin{abstract}
AIM: This paper compares the impact of leadership behaviours on the discretionary power, well-being, and affective commitment of police officers from Italy and the United Kingdom (UK). In contrast to Italy, UK is an example of a core-New Public Management (NPM) country that has implemented reforms, in turn, changing the management and administration of public organizations. Consequently, it is expected that there will be significant differences in the behaviour of police officers. In particular, the paper examines the antecedents and outcomes of police officers' well-being.

Methods: The study involves collecting and analyzing survey data using Structural Equation Modelling from 220 Italian and 238 UK police officers.

Findings: There was a significant path from Leadership to Discretionary Power to Employee Wellbeing to Affective Commitment - at least for the Italian sample. There was no have a significant link between leadership and discretionary power for the UK. Discretionary power was low for both groups as was affective commitment. Authentic leadership and discretionary power explained approximately a third of well-being, particularly discretionary power. Together, directly and indirectly (mediated by well-being), they explained at least a third of police officer commitment to their organization. Well-being appears to be the key to ensuring effective police officers.

Limitations: The limitation of this paper includes the use of cross-sectional data (Podsakoff et al., 2003). However, a common latent factor (CLF) was included, and several items that were
\end{abstract}


explained by common method variance were controlled, as per George and Pandey's recommendations (2017). Additionally, a Harmon's single factor test was applied to the data. Main Contribution: The UK police officers have significantly lower commitment compared with the Italian police officers (non-commitment), and both Italian and UK police officers have less discretionary power and well-being compared with, police from the United States of America (USA) and other street-level bureaucrats (SLBs). The findings suggest that present police leadership behaviours erode police officer discretionary power and well-being, leading to low organizational commitment. Leadership training will better prepare managers to ensure the wellbeing of police officers working under conditions of work intensification.

Plain language: The UK police officers have significantly lower commitment compared with Italian police officers, and Italian and UK police officers have less discretionary power and well-being compared with USA police officers. Leadership models that enhance employee well-being rather than efficiency targets must be a priority if police are to be prepared to cope effectively with emergencies and pandemics. 


\section{Introduction and background}

The behaviour of police officers depends on multiple factors. Police officers are an example of Street Level Bureaucrats (SLBs) who deliver public services. However, they differ from some other SLBs because of their highly stressful work life.

Constant exposure to people suffering distress and pain, threats to officer safety and wellbeing, having to be in control of emotions when provoked, the inconclusive nature of police work, the responsibility of being in possession of a firearm and more importantly the responsibility of protecting the lives of citizens have been recognized as significant sources of stress (Purba \& Demou, 2019, 1286).

Austerity-driven funding models dominate police service delivery decision-making in the UK at a time of increasing demand, which has reduced their well-being (Hesketh, Cooper \& Ivy 2017). Lipsky (1980) argues that police officers are similar to other SLBs because they are all public sector employees servicing the public, and demand for services always outstrips supply. Consequently, they develop and adopt coping strategies to decide 'who' gets 'what'. SLBs then actively differentiate their behaviour towards different citizens deciding whether to apply the rule of law or not, according to the institutionalized stereotyping prevailing in the society at large (Lipsky 1980, 142). However, such a perspective ignores the impact of four decades of reform actively aimed at reducing the power of SLBs in some countries.

New Public Management (NPM) reforms involved changing the management practices in some countries, however, not all countries implemented the same changes. Pollitt and Bouckaert $(2017,121)$ categorized core-NPM countries as those that implemented significant reforms, such as the United Kingdom (UK). In contrast, the 'ex-Napoleonic Mediterranean states' were termed 'NPM laggards' because countries like Italy adopted a far more legalistic approach, and consequently few changes in management practices were successfully implemented (Politt \& Dan, 2011). The implication of the reforms is the discretionary power 
of SLBs in core-NPM countries should have fallen, but not in Napoleonic Mediterranean countries.

According to Tummers (2011), SLBs' discretionary power depends mostly on the 'checks and balances' in place, which in turn, depends on the leadership behaviour in place determining work practices. In an earlier paper comparing police officer discretionary power in the USA (core-NPM countries) with Malta ('NPM laggards'), the discretionary power of police officers in the USA was much higher than the discretionary power of Maltese police officers (Farr-Wharton, Azzopardi, Brunetto, Farr-Wharton, Wojtarowicz, \& Shriberg, 2016), which was not expected. One explanation is that police officers' outcomes are determined by a multitude of factors, including the leadership behaviours of managers. Discretionary power is important because it affects employee outcomes. For example, Brunetto, Farr-Wharton, FarrWharton, Shacklock, Azzopardi, Saccon \& Shriberg (2017b) found that high discretionary power was associated with high affective commitment for police officers from the USA, however, the USA, Australia and Malta; police had low satisfaction with management. They concluded, "...there appears to be no expectation that police management will be effective in managing police activities" (Brunetto et al., 2017b, 759). Cordner (2016) states that managers regularly attempt to thwart and repress police officer's discretionary power by using bureaucracy and red tape to impose compliant behaviour, without acknowledging the consequences on their well-being. Additionally, Cronin et al., (2017) argue that poor leadership and management practices can be partially explained by the command hierarchical structure, which expects police officers to follow policies, laws and organizational expectations, even if this compromises well-being.

Whilst it is acknowledged that management practices are dependent on the accepted leadership behaviours (Cronin et al., 2017; Brunetto et al., 2017a), the study of public sector leadership, especially police leadership behaviour has not received strong interest from 
scholars compared with other disciplines such as organizational behavior. When public administration leadership is examined, the focus has almost exclusively been on improving employee performance (Tummers \& Knies, 2015, 433). One reason is that public sector managers are informed predominantly by rational-technical mindset, which uses control embedded within traditionally supported bureaucratic practices (Getha-Taylor, Holmes, Jacobson, Morse, \& Sowa, 2011). However, there is increasing criticism of public sector, particularly police leadership, post the implementation on NPM because of the rising incidence of bullying, work harassment and stress perceived by employees. Such a work environment is often caused by inexperienced managers 'juggling' organizational demand to cut costs, with a growing demand for services (Estere et al., 2017; Farr-Wharton et al., 2016). As a result, the well-being of police officers in the UK has been compromised (Wolter et al., 2019). Consequently, it is leadership behaviour that appears to be the pivotal issue determining the outcomes for police officers. For this reason, this paper examines the impact of a leadership model - authentic leadership - from Positive Organizational Behaviour (POB).

Authentic leadership (AL) is a type of positive leadership behaviour. It comprises a combination of four behaviours, including 'emotional cognition and control', which refers to leaders' control over their emotions and how this affects others. The greater their ability to understand and control their emotions, the greater their likelihood of engaging in 'relational transparency'. Relational transparency results in workplace relationships underpinned by trust and meaningful interactions, which also promotes ethical decision-making and 'rational processing,' because of their openness to receive input from relevant stakeholders, rather than just friends (Avolio et al., 2009). Past research suggests that when authentic leadership behaviours are used, the outcome is likely to be increased employee well-being (Ilies et al., 2005). Employee well-being is essential for many reasons, not least because it is a priority for 
advancing humanity. It is listed as the third United Nations (UN) Sustainable Development Goal (SDG\#3) to achieve "good health and well-being".

However, public sector scholarship has only recently become interested in the issue of employee health and well-being. One problem in understanding employee well-being is that each discipline defines it differently. In the past, most well-being measures were related to performance (such as job satisfaction), however more recently there has been growing acceptance of conceptualizing well-being in terms of psychological attributes (Forgeard et al., 2011). In this paper, employee well-being is defined as comprising the psychological attributes - hedonic (moods and emotions) and eudaimonic (the extent to which employeess' work is consistant with their values) (Forgeard et al., 2011). The well-being of police officers is increasingly perceived as important because of the rise of stress-related illnesses amongst police officers. According to Purba and Demou (2019, 1286), the culture of policing must change from one that "values self-reliance and stoicism to one that promotes the overall wellbeing of their employees".

Public administration theory has proved inadequate for explaining employee behaviour (Vigoda-Gadot \& Meisler, 2010). Grimmelikhuijsen et al., (2017) argue that there are benefits to considering theories from outside the public administration discipline in order to provide greater insight into the real issues. Consequently, this paper draws on 'Conservation of Resources' (COR) theory (Hobfoll, 1989) to explain the behavior of SLBs'. COR theory argues that employees are motivated to achieve high well-being and therefore, will behave accordingly. This paper uses SLB and COR theories to explain the impact of authentic leaders on police SLBs' perception of discretionary power and well-being, and in turn, their commitment to the police department (called affective commitment. The research question guiding the study is: 
RQ1: What is the impact of Authentic Leadership on the discretionary power and wellbeing and in turn, the affective commitment of Italian and UK police officers?

RQ2: What are the similarities and differences in the impact of Authentic Leadership, on the discretionary power and well-being and in turn, the affective commitment on Italian and UK police officers?

The contribution of this paper is that it adds insight into the behaviour of one type of SLB police officers, using COR theory that extends the body of public administration theory by providing a comparative depth of understanding. In particular, the use of a COR theoretical lens provides a more meaningful explanation of the impact of public sector leadership on SLBs' discretionary power and well-being. The paper is structured as below. The next section reviews the extant literature from which hypotheses are derived. Section 3 discusses the research methodology, including the statistical methods used to analyze the data. This is followed by the results, discussion and conclusion.

\section{Literature review}

\subsection{Street Level Bureaucrats (SLBs) Theory}

SLB theory provides an understanding of police officer behaviour when faced with demand outstripping supply. Lipsky (1980) explained that SLBs use their discretionary power to 'cut corners' and establish routines that ration services. These routines help them to cope. However, chronic levels of austerity for the past few decades have changed the work-life of SLBs with pay cuts and increased workloads negatively affecting their motivation and job performance (Esteve et al., 2017). Further, austerity-driven reforms have increased red tape, and increased bureaucracy (Lipsky, 2010; Pollitt and Bouckaert, 2017) and Cordner (2016) argues that in the case of police officers, managers have used red tape and increased bureaucracy to ensure police officer's discretionary was reduced. 
One reason that could explain why SLB theory has failed to capture the complexity involved in understanding their behaviour is that public administration research is underpinned by a belief that outcomes are a product of rational decision-making that can explain 'who' gets 'which' services. However, such a belief is flawed because public administration theories do not understand that employee behaviour is influenced by how work tasks affect emotions and well-being. This “... neglect [of] the emotional base of administrative activities ... [has led to

a lack of empirical research] ... in relation to public organization theory" (Vigoda-Gadot \& Meisler, 2010, 82). As such Vigoda-Gadot and Meisler $(2010,84)$ argue that:

... emotions provide another tool for improving performance and may serve as a complementary arsenal in the search for better public services.

For the last two decades, austerity-led reforms have dominated government change agenda, complicating the desire to change service delivery models with significant budget cuts, forcing SLBs to accept agendas such as 'to do more with less' (Pollitt \& Bouckaert 2017). Rational public administration fails to explain the widespread use of work harassment, overwork and negative working conditions (Brunetto et al., 2015) in the public sector. Tummers (2017) argues that most research has focused on the impact of discretionary power on clients, rather than the outcomes on SLBs. This paper addresses the gap. It is only by better understanding how leadership behaviours affect SLBs that the public administration discipline can gain real insight.

\subsection{Conservation of Resources Theory}

COR theory argues that it is an organization's responsibility to ensure that employees have adequate physical, psychological and social resources to do their job (Hobfoll, 2011). Hobfoll (2001) categorizes four types of resources: objects, conditions, personal attribute and energy. The theory argues that employees are motivated to undertake actions that will develop or 
conserve their resources to maintain their well-being because of our 'human.behavioral genetics" (Hobfoll et al., 2018, 103). In particular, they argue that:

COR theory posits that stress occurs $(a)$ when central or key resources are threatened with loss, $(b)$ when central or key resources are lost, or $(c)$ when there is a failure to gain central or key resources following significant effort.

This leads to principles that predict how employees will behave. The first principle of COR is that resource losses have a bigger impact than a resource gain (Halbesleben et al., 2014). The reason is because a perceived resource loss generates negative physiological, cognitive, emotional, and social responses (Hobfoll, 2001). The second principle is that "people must invest resources in order to protect against resource loss, recover from losses, and gain resources" (Hobfoll et al., 2018, 105) such as using their savings whilst they look for another job as a way of preserving their existing well-being. The third principle is that when employees perceive a loss of resources is imminent, the value of a resource gain becomes more important (Halbesleben, Neveu Paustian-Underdahl \& Westman, 2014). Finally, when employees perceive that their reservoir of resources has been drained, they will act defensively to preserve their well-being, and this could include irrational behaviour. Additionally, resource gain or loss does not exist in a vacuum; instead, the conditions that create or thwart resource growth reflects the prevailing organizational culture either providing 'support' resources - called 'resource caravan passageways' or eroding them (Hobfoll et al., 2018).

The argument examined in this paper is that when poor leadership exists, the conditions exist to promote poor discretionary power, which generates negative physiological, cognitive, emotional, and social responses (Hobfoll, 2001), such as low well-being. Because police officers have low well-being, they conserve their resources, and instead of having a high commitment to their organization, they use their resources to pursue other activities such as sport that is likely to build their well-being. In summary, employees make decisions about whether their organizations are positively contributing or negatively eroding their well-being 
and regulate their work behaviour accordingly. The next section examines how one public sector organization uses its leadership and management behaviours to affect the outcomes of its police officers.

\subsection{Authentic Leadership (AL)}

Authentic leaders are self-aware and consequently solicit advice from relevant stakeholders in a respectful manner, before making ethical, rational decisions. The reality is that many SLBs perceive increasing levels of work harassment, overwork, limited resources and high bureaucracy because of poor public sector leadership behaviour (Van Thielen et al., 2018; Brunetto et al., 2015). In particular, Kellie and Ran (2015) argue that AL embraces the ethical and rational processing dimensions, which are presently missing from public sector leadership. Also missing is relational transparency, which Newman, Guy and Matracci (2009) argue can be enhanced by effective feedback loops, which in turn, enhances police officer wellbeing.

More recently, Lopez et al., (2015) found that AL significantly improved group cohesion and identity of police officers in Spain. In addition, Arnatt and Beyerlein (2014) in a study of the impact of leadership behaviour on USA law enforcement special operations teams identified that it was not enough to policing-specific operational knowledge and skills. In summary, Arnatt and Beyerlein (2014) found that it was authentic leadership behaviours that appeared to strengthen operational performance. Hence, it is important to compare the influence of AL on Italian and English police officers. This is relevant because both nursing and policing can be stressful (Benedek et al., 2007; Purba \& Demou, 2019). Using COR theory as a framework, leadership behaviour is evident for the police officer whenever they interact with their supervisor. If poor leadership behaviours are perceived then over time, then it is likely that their well-being will be compromised. If the situation becomes chronic, then it could 
force police officers to act according to the fourth principle and reduce their energy at work as a way of preserving their well-being, and re-focusing their energy away from work.

\subsection{Discretionary Power}

Discretionary power refers to an SLBs perception of choice in determining 'who' and 'what' clients will receive (Lipsky, 1980). Discretionary power is defined as a process for sharing of power to ensure employees perceive self-efficacy (Spreitzer, 1995, 2007). However, Wong and Laschinger $(2014,947)$ argue that:

"The biggest challenge for establishing empowering workplaces may reside in the role of effective leadership."

They found that AL was a significant predictor of empowerment for Canadian nurses (Wong \& Lasinger, 2014) and therefore, we expect to replicate the same relationship for Italian and English police officers.

H1: Authentic Leadership behaviour is associated with high discretionary power for police officers.

Additionally, one of the aims of NPM was to standardize service delivery, and that involved reducing the discretionary power of SLBs. Whilst the belief was that the discretionary power of police officers was lower in those countries that have implemented NPM reforms; Brunetto et al. (2017) confirmed this finding for Australian police only. It was not confirmed in the case of USA police officers. The explanation was that whilst the USA is a core-NPM country, at the time of the research, the reforms had been implemented only at the upper levels of the police hierarchy, leaving the discretionary power of police officers relatively untouched (Shane, 2011; Brunetto et al., 2017a, b). However, it is expected that English police officers will perceive a similar discretionary power compared to Australian police officers because both are core-NPM countries. It, therefore, should have lower discretionary power compared with Italian police (NPM-laggard). The hypothesis is: 
H2: Italian police officers are likely to have higher discretionary power compared with English police officers.

\subsection{Employee Well-being}

At stated, previous research has conceptualized well-being in multiple. The limitation of previous studies about how leadership behaviours affect well-being is that they have:

...largely neglected research on employee health and well-being in favor of employee performance ... employee well-being has generally not been considered as an important outcome in and of itself ... the impact of a leader's behavior on employee well-being is underdeveloped and narrowly-focused" (Inceoglu, Chu, Plans \& Gerbasi, 2018, 179).

As stated, we adopt Forgeard et al. (2011) and Brunetto et al. (2011) conceptualization, which comprises the hedonic dimension and the eudaimonic dimension (Brunetto et al., 2011, 2016, Forgeard et al, 2011). As such it seeks to capture "the quality of working lives, and it may be seen as a major determinant of productivity at the individual, enterprise, and societal levels" (Schulte \& Vainio 2010, 422). Using the COR lens, high well-being is achieved when "individuals have the psychological, social and physical resources they need to meet a particular psychological, social and/or physical challenge" (Dodge et al., 2012, 230). In terms of SLBs, Brunetto et al. (2018) identified that high discretionary power predicted high wellbeing for nurses in Australia, Italy and the UK. We, therefore, expect to replicate a similar relationship for police officers, because in terms of COR theory, if SLBs have enough resources they are likely to perceive discretionary power, which they are likely to interpret as positive and this is likely to build their sense of well-being.

\section{H3: High discretionary power is associated with high employee well-being.}

Research has been undertaken, which compares the well-being of different types of employees in different countries. For example, in Australia, police SLBs perceive lower well-being compared with nurses (Brunetto et al., 2014). However, a comparison of nurses' well-being in Australia, UK and Italy identified that UK healthcare SLBs scored the lowest (Brunetto et al., 
2017). In terms of police officers, Maltese police officers have a lower well-being compared with USA police officers (Farr-Wharton et al., 2016). Based on this comparison, we expect Italian police officers to perceive higher well-being compared with UK police officers.

H4: Italian police officers are likely to have higher well-being compared with English police officers.

\subsection{Affective Commitment}

Affective commitment refers to employee identification with, and emotional attachment to an organization (Allen and Meyer, 1990). Farr-Wharton et al. (2016) found that police officers had low organizational commitment in the USA and Malta. Suggesting that in terms of COR theory, neither organization had provided the resources to build their well-being. Similarly, Brunetto et al. (2014) identified a comparable situation for Australian police officers. Conway et al. (2014) suggest that years of austerity led change has channelled UK SLBs to perceive broken psychological contracts, in turn, reducing their affective commitment. In terms of COR theory, a perception of a broken psychological contract is likely to lead to a fall in well-being (H5). Interestingly, it did not change their commitment to their colleagues or the public. The last COR principle suggests that the result of such actions over time is likely to be a reduction in work commitment in an attempt to preserve their well-being (H5). For this reason, we expect affective commitment to be low in both countries because austerity-driven funding models have reduced the number of SLBs per capita in most countries (Esteve et al., 2017) (H8). On the other hand, those employees who are satisfied with their leaders and are committed to the organization, also tend to have low turnover (Azanza, Moriano, \& Molero, 2013) (H7). These hypotheses address a gap in the literature about how authentic leadership impacts SLBs. The hypotheses are:

H5: High well-being is associated with high affective commitment. 
H6: High discretionary power is associated with high affective commitment.

H7: Well-being mediates the relationship between AL and affective commitment.

H8: Both UK and Italian police officers have low affective commitment to their organizations.

\section{Research Methods}

Population: The sample of UK police officers came from a region in the North of England where over 5000 police officers are stationed. The sample of Italian police officers came from the Veneto region in the North of Italy, servicing a comparable population and size.

Survey: A paper survey comprising validated instruments was distributed to 500 police officers in one region of Italy and the UK. In total, the Italian sample was n=220. However, only 203 surveys were useable (response rate of $44 \%$ ). The UK sample was $n=238$. However, only 228 surveys were useable (response rate of $46 \%$ ).

Participants: The Italian sample comprised 165 males, and 55 females, 131 (almost 60\%) were aged 33 years of age or less (Gen Y); 72 aged between $34-48$ years of age and 11 aged over 48 years of age. In terms of their rank, 136 were constables, 13 were sergeants, and the remaining 39 were inspector or above (17 failing to disclose). The UK sample comprised 146 males, 84 females ( 8 did not disclose); of which 144 (almost 50\%) were aged less than 33 years of age (Gen Y); 88 were aged between $34-47$ years of age, and 23 (almost 10\%) were aged over 48 years of age. In terms of rank, 217 (over 90\%) were constables, 17 were sergeants, and 2 were inspectors or higher ( 2 did not disclose).

Measures, Instrument reliability and validity

Instruments: We used validated scales to operationalize the structural model. These were each measured on a six-point Likert-type scale, ranging from ' 1 = strongly disagree' to ' 6 = strongly agree.'Authentic Leadership was measured using the 8 item Authentic Leadership 
questionnaire developed by Walumbwa et al. (2008). Discretionary power was one of four scales developed by Spreitzer (1995) to capture employee psychological empowerment. Employee well-being was measured using a four-item scale developed by Brunetto, FarrWharton, and Shacklock (2011). An example includes 'Overall, I am reasonably happy with my work life'. To measure Affective commitment an eight-item scale developed by Allen and Meyer (1990). A sample item is, 'I feel a strong sense of belonging to my organization'. Items displayed appropriate normality evidenced by skewness and kurtosis scores of between -2 and +2. A Harmon's single factor test was applied to the data and evidenced that $38 \%$ of the variance is explained by one factor - indicating a low likelihood of common method bias.

In preparation for path and latent mean model comparison, confirmatory factor analysis was assembled. The correlation for the reverse-coded item within affected commitment was low (below .5 after inversion), for both the Italian and UK sample. As such, the item was omitted. Additionally, the modification indices noted that the model could be improved with the inclusion of covariance between Authentic Leadership items 1 and 2, 6 and 7, and Affective Commitment Items 1 and 2 (for both samples). The resultant models had an appropriate fit. The Italian sample had a Chi-Squared over Degrees of Freedom metric of 1.929 (appropriate below 5), a Corrected Fit Index of .94 (optimal over .95, but acceptable over .9), a Tucker-Lewis Index of .93 (optimal over .95, but acceptable over .9), and a Root Mean Square Error Approximation of .068. Similarly, the UK sample had Chi-Squared over Degrees of Freedom metric of 1.934, a Corrected Fit Index of .95, a Tucker-Lewis Index of .94, and a Root Mean Square Error Approximation of .064. For the Italian sample, the instrument reliability, as well as the convergent and discriminant validity was good. The composite reliability (CR) (appropriate over .7), average variance extracted (AVE) (appropriate when above .5), the Maximum Squared Variance (MSV) (appropriate when below the AVE), and the inter- 
construct correlations (appropriate when the Square Root of the AVE is greater than the interconstruct correlations), for both samples, is displayed below.

\section{Results}

The analysis for latent mean equivalent testing may be conceptualized around three analytical steps (Byrne, 2016). The first compares the equivalence of factor loadings across the two groups by comparing the $\triangle$ CFI metric. The CFI for the UK model was .950 , and the Italy model was .943, leaving a $\triangle \mathrm{CFI}$ of .007. This is lower than the cut off of .01. Byrne (2016) recommends the $\Delta \mathrm{CFI}$ test as an appropriate tool for comparisons factoring in low sample sizes (as per the case in this analysis). The conclusion from this test is that the factor loads are invariant across the two groups. The second step in latent mean equivalent testing examines the mean differences of the latent constructs across the two groups, an important process for testing components of the hypotheses. Table 1 highlights the mean difference between the UK and Italian samples. The mean difference analysis indicates that the UK has significantly higher Authentic Leadership and Affective Commitment and significantly lower Well-being. On the other hand, discretionary power is equivalent across both groups.

The final step of analysis examined the differences in the path models between the two groups. Figure 1 below highlights the standardized regression weights of the hypothesized paths for both samples, in addition to the $\mathrm{R}^{2}$ values. The $\Delta \mathrm{X}^{2} / \mathrm{df}$ of the constrained and unconstrained model was $23.34 / 16$, which is no significant $(\rho=.105)$, that the models were equivalent; however, the paths possessed variations across the two groups. The proceeding table (Table 2) indicates the results from the bootstrapped mediation testing method, highlighting the direct and indirect effects. 


\section{Discussion}

This paper aims to explain the behaviour of police officers in Italy and the UK. The reason for the comparison is that the UK is typical of a core-NPM country that has implemented many reforms and Italy is an example of a NPM-laggard country where few reforms were implemented (Pollitt \& Bouckaert, 2017; Politt \& Dan, 2011). The paper used SLB and COR theories to firstly examine and compare the impact of authentic leadership on the discretionary power and well-being and in turn, the affective commitment of police officers.

The path and mean analysis show that all but three of the hypotheses are supported. Overall, there is a significant path from Leadership to Discretionary Power to Employee Wellbeing to Affective Commitment - at least for the Italian sample. The UK sample does not have a significant link between leadership and discretionary power. Hence, $\mathrm{H} 1$ is only partially accepted. There are also significant differences across the variables except for discretionary power. The discretionary power of UK and Italian police officers are similarly low; hence $\mathrm{H} 2$ is rejected. Also, whilst both countries had low commitment, Italian police officers are significantly more committed compared with UK police officers, rejecting hypotheses H8.

Based on SLB theory, past research about police SLBs shows that they have discretionary power to make decisions about 'who' gets 'what' as a coping measure for dealing with the problem that demand exceeds supply (Lipsky, 1980). However, decades of austerity-led reform has reduced the discretionary power of SLBs, especially that of police officers. Past research suggested that one factor negatively affecting their perception of discretionary power is the quality of leadership behaviours (Cordner, 2016; Cronin et al., 2017). However, in this study, the variance of leadership behaviours accounted for only a small part of the discretionary power of police officers ( $2 \%$ for UK police and $8 \%$ for Italian police), and the impact of leadership on the discretionary power of UK police officers was not significant; hence H1 is only partially 
accepted in the case of Italian police only. This is at odds with previous research by FarrWharton et al. (2016) concerning USA and Maltese police officers as well as Arnatt and Beyerlein's (2014) findings about USA special forces They argued that effective leadership was essential for ensuring empowering workplaces.

Additionally, as stated, in this paper, there was no difference in the discretionary power of police officers in Italy and the UK, hence $\mathrm{H} 2$ is rejected. One potential explanation could be that only the impact of authentic leadership was tested, and the findings may have been different if the impact of autocratic leadership was examined because this is the type of leadership found in low quality workplaces (De Hoogh et al., 2015). On the other hand, as expected, there were significant paths from leadership to well-being and from discretionary power to well-being, with evidence of discretionary power partially mediating the path from AL to well-being for Italian police officers. The variance of AL and discretionary power explained over a third of Italian police officers well-being, compared with just over a quarter of the well-being of UK police officers, in turn supporting H3. These findings are somewhat consistent with the findings from a meta-analysis by Purba and Dermou $(2011,2)$ that identified the stressors affecting the well-being of police officers. They identified the occupational stressors having the most negative impact on police officers' well-being as the:

... lack of support from superiors and organization, long working hours, inadequate work schedule, high mental/intellectual demand, job demand, organizational climate, organizational culture and low decision latitude [discretionary power].

In contrast, in this paper, the impact of leadership behaviours (which largely determines the level of resources available to SLBs) did not have a direct effect.

Using an SLB theoretical lens, these findings suggest that police officers perceive some discretionary power, which is consistent with past research by Cordner (2016) and Cronin et al. (2017). The significant path between discretionary power and well-being is consistent with previous research for another type pf SLB - nurses. For example, Brunetto et al. (2018) found 
that discretionary power significantly affected the well-being of nurses in the UK, Australia and Italy.

As expected, both the UK and Italian police officers perceived limited well-being. H4 is supported because, as expected, the Italian police officers perceived higher well-being compared with UK police officers. These findings are consistent with COR theory because when SLBs perceive only limited resources (evident in their perception of low discretionary power), and consequently, it is likely to negatively impact their sense of well-being (the fourth principle of COR).

Additionally, it was expected that police officers would have low affective commitment. However, the UK police officers had significantly lower commitment compared with the Italian police officers (non-commitment) - suggesting that the organization has a problem with police morale. While these findings are consistent with the low commitment of SLBs to the organization (Pollitt \& Bouckaert, 2017; Esteve et al, 2017; Brunetto et al, 2015), these findings are troubling for an organization that expects its employees to put their 'life on the line' to protect society. However, it may be a similar situation to Conway et al. (2014), where a perception of a broken psychological contract had likely led to a fall in employee wellbeing; but does not affect their commitment to their colleagues or the public - only the organization. Consequently, until those who manage police officers use leadership models likely to support and enhance their well-being, rather than using an austerity-driven resourcing focus, police officers will likely perceive falling commitment to their police organization. These findings do suggest that the work context for police officers is changing because of increased work intensity.

The limitation of this paper includes the use of cross-sectional, which is always susceptible to common method bias (Podsakoff et al., 2003). However, a CLF was included, 
and several items that were explained by common method variance were controlled, as per George and Pandey's recommendations (2017).

\section{Conclusion}

Two theoretical lenses have been used in this paper to explain the behaviour of police officers. The findings challenge the perspective that SLBs have discretionary power to make decisions about 'who' gets 'what'. Police officers in both a core-NPM country and an NPMlaggard country perceive minimal discretionary power. It seems likely that decades of austerity-led selective reforms have changed the work context of SLBs, as argued by Esteve et al. (2017) and Brunetto et al. (2018). The findings about employee well-being add further weight about the lack of suitability of existing public administration theories that neglect the emotional basis of employees (Vigoda-Gadot \& Meisler, 2010; Tummers, 2017). On the other hand, in line with Grimmelikhuijsen et al., (2017) suggestion, this paper used COR theory from the psychology disciple to explain SLB outcomes. Far more research about the type and impact of leadership on SLB outcomes is required. More research is required to examine how to ensure high well-being amongst different types of SLBs, especially police officers and the use of theories from Psychology may provide a complementary research framework.

In this paper, the use of COR theory (Hobfoll, 1980; 2011, Hobfoll et al. 2018) provided greater insight into how a lack of perceived resources (such as discretionary power) explains employee well-being. In this case, it seems likely that, especially in the case of UK police officers, police officers have withdrawn their commitment to the organization as a way of preserving their well-being. If they do not, they are likely to become a 'burnout' statistic (Hobfoll et al., 2018). The surprising finding is that there is no evidence of a direct impact from authentic leadership behaviours for UK police officers and only a minimal impact for Italian police officers. One explanation is that autocratic leadership behaviours dominate policing 
because of the command structure of policing (Cordner, 2016). This paper did not test for such behaviour. Further studies should consider examining SLBs behaviour using complementary research frameworks along with traditional public administration theories to build an evidencebased blueprint from which those who manage SLBs can develop effective ways of achieving high performance and well-being outcomes simultaneously, even under conditions of austerity.

The implication for policing is that the quality of the supervisor-police officer relationship matters in determining their outcomes. Those managing police officers must be upskilled in authentic leadership behaviours so as to support and enhance their well-being and promoted greater commitment to their organization Hence training managers in using authentic leadership behaviours will promote better relationships (Brunetto et al, 2019). Effective relationships will support police officers' to preserve their wellbeing. New leadership models that prioritize employee well-being above efficiency are required to ensure police officers have the physical, psychological and emotional resources are required to perform their job well 


\section{References}

Arnatt, M., \& Beyerlein, M (2014) An empirical examination of special operations team leaders' and members' leadership characteristics Policing; An International Journal of Police Strategies and Management 37 (2) 438-453

Avolio, B. J., Walumbwa, F. O., \& Weber, T. 2009. Leadership: Current theories, research, and future directions. Annual Review of Psychology, 60: 421-449.

Brunetto, Y., Farr-Wharton, R. and Shacklock, K. (2011), Using the Harvard HRM model to conceptualize the impact of changes to supervision upon HRM outcomes for different types of public sector employees, International Journal of Human Resource Management, 22 (3), pp. 553-573.

Brunetto, Y., Shacklock, K., Teo, S \& Farr-Wharton, R (2014) The impact of management on the engagement and well-being of high emotional labour employees International Journal of Human Resource Management 25 (17) 2345-2363

Brunetto, Y., Xerri, M., Trinchero, E., Farr-Wharton, R., Shacklock, K., Borgonovi, E, (2015) Public-Private Sector Comparisons of Nurses' Work Harassment Using SET: Italy and Australia Public Management Review 18 (10), 1479-1503

Brunetto, Y, Teo, S., Farr-Wharton, R., Shacklock, K \& Shriberg, A (2017a) Individual and organizational support: does it affect red tape, stress and work outcomes of police officers in the USA? Personnel Review 46 (4) 750-766

Brunetto, Y., Farr-Wharton, B., Farr-Wharton, R., Shacklock, K., Azzopardi, J., Saccon, C., Shriberg, A (2017b) Comparing the impact of management support on police officers' perceptions of discretionary power and engagement: Australia, USA and Malta, The International Journal of Human Resource Management http://dx.doi.org/10.1080/09585192.2017.1375964

Brunetto, Y., Xerri, M., Trinchero, E., Beattie, R., Shacklock, K., Farr-Wharton, R., \& Borgonovi, E. (2018). Comparing the impact of management on public and private sector nurses in UK, Italy and Australia. Public Management Review, 20(4), 525-544

Brunetto, Y., Dick, T., Xerri, M., Cully, A (2019) Building capacity in the healthcare sector: A strengths based approach for increasing employees' well-being and organisational resilience Journal of Management \& Organisation http://dx.doi.org/10.1017/jmo.2019.53

Chan, K. W., \& Lam, W. (2011). The trade-off of servicing empowerment on employees' service performance: Examining the underlying motivation and workload mechanisms. Journal of the Academy of Marketing Science, 39(609-628).

Cordner, G (2016) The unfortunate Demise of Police Education Journal of Criminal Justice Education, 27 (4), $485-496$

Cronin, S., McDevitt, J., \& Cordner, G. (2017). Police supervision: Perspectives of subordinates. Policing: An International Journal of Police Strategies \& Management, 40(1), 26-41

Conway, N. Kiefer, T. Hartley, J and Briner, R. (2014). Doing more with less? Employee reactions to psychological contract breach via target similarity or spillover during public sector organizational change. British Journal of Management 25, 4, p737-754.

De Hoogh, A. H., Greer, L. L., \& Den Hartog, D. N. (2015). Diabolical dictators or capable commanders? An investigation of the differential effects of autocratic leadership on team performance. The Leadership Quarterly 26(5), 687-701.

Dodge, R., Daly, A., Huyton, J \& Sanders, L (2012) The challenge of defining well-being. International. Journal of Wellbeing, 2, 222-235 
Esteve, L., Schuster, C., Albareda, A., \& Losada, M (2017) The effects of doing more with less in the public sector: Evidence from a large-scale survey Public Administration Review, 77 (4), 544-553

Forgeard, M. J. C., Jayawickreme, E., Kern, M. \& Seligman, M. E. P. (2011). Doing the right thing: Measuring well-being for public policy. International Journal of Wellbeing, 1(1), 79-106.

Getha-Taylor, H., Holmes, M. H., Jacobson, W. S., Morse, R. S., \& Sowa, J. E. (2011). Focusing the public leadership lens: research propositions and questions in the Minnowbrook tradition. Journal of Public Administration Research and Theory, 21(suppl 1), i83-i97.

Grimmelikhuijsen, S., Jilk, S, Olsen, A.L. and Tummers, L.G. (2017) Behavioral public administration: Combining insights from public administration and psychology. Public Administration Review, 77: 45-56.

Hesketh, I., Cooper, C.L., and Ivy, J., (2017). Well-being and Engagement in Policing: The Key to Unlocking Discretionary Effort? Policing: A Journal of Policy and Practice, $11(1), 6273$.

Hobfoll, S. E. (1989). Conservation of resources: A new attempt at conceptualizing stress. American Psychologist, 44, 513-524.

Hobfoll, S.E. (2001), The influence of culture, community, and the nested-self in the stress process: advancing conservation of resources theory, Applied Psychology, 50 (3), 337421.

Hobfoll, S.E. (2011), Conservation of resource caravans and engaged settings, Journal of Occupational and Organizational Psychology, 84 (1) 116-122.

Hobfoll, S. E., Halbesleben, J., Neveu, J.-P., \& Westman, M. (2018). Conservation of resources in the organizational context: The reality of resources and their consequences. Annual Review of Organizational Psychology and Organizational Behavior, 5: 103128.

Inceoglu, G., Chu, C., Plans, D., \& Gerbasi, A., (2018) Leadership behavior and employee well-being: An integrated review and a future research agenda The leadership Quarterly, 29 179-202

Ilies, R., Morgeson, F. P., \& Nahrgang, J. D. (2005). Authentic leadership and eudaemonic well-being: Understanding leader-follower outcomes. The Leadership Quarterly, 16, 373-394.

Lipsky, M., (1980). Street-level bureaucracy: dilemmas of the individual in public services, New York: Russell Sage Foundation.

Lipsky, Michael, (2010). Street-Level Bureaucracy: Dilemmas of the Individual in Public Services 30th anniv., New York: Russell Sage Foundation.

Pollitt, C. \& Dan, S. (2011). The impacts of the new public management in Europe: A Meta analysis. COCOPS working paper no. 3.

Pollitt, C. and Bouckaert, G. (2017). Public management reform: a comparative analysis-into the age of austerity: Oxford University Press.

Purba, A., Demou, E. (2019) The relationship between organizational stressors and mental well-being within police officers: a systematic review. BMC Public Health 19, 1286 (2019). https://doi.org/10.1186/s12889-019-7609-0

Tummers L.G. (2011) Explaining the willingness of public professionals to implement new policies: a policy alienation framework. International Review of Administrative Sciences 77 (3), 555-581.

Tummers, L. and E. Knies. (2016). 'Measuring Public Leadership: Developing Scales for Four Key Public Leadership Roles', Public Administration, 94, 2, 433-51. 
Tummers, Lars. (2017). The relationship between coping and job performance. Journal of Public Administration Research and Theory 27: 150-162.

United Nations (2020), "The Sustainable Development Goals Progress Report." https://www.un.org/sustainabledevelopment/health/

Van Gelderen BR, Bakker AB, Konijn EA, Demerouti E. (2011). Daily suppression of discrete emotions during the work of police service workers and criminal investigation officers. Anxiety Stress Coping 24:515-37

Vigoda-Gadot, E. and Meisler, G. (2010), "Emotions in management and the management of emotions: the impact of emotional intelligence and organizational politics on public sector employees", Public Administration Review, Vol. 70 No. 1, pp. 72-8

Walumbwa, F., Avolio, B., Gardner, W., Wernsing, T., \& Peterson, S. (2008). Authentic leadership: development and validation of a theory-based measure. Journal of Management, 34, 89-126.

Wolter, C., Santa Maria, A., Wörfel, F., Gusy, B., Lesener, T., Kleiber, D., \& Renneberg, B., (2019). Job Demands, Job Resources, and Wellbeing in Police Officers - A Resource

Oriented Approach. Journal of Police and Criminal Psychology, 34 (1), 45-54 
Figure 1: Path Model

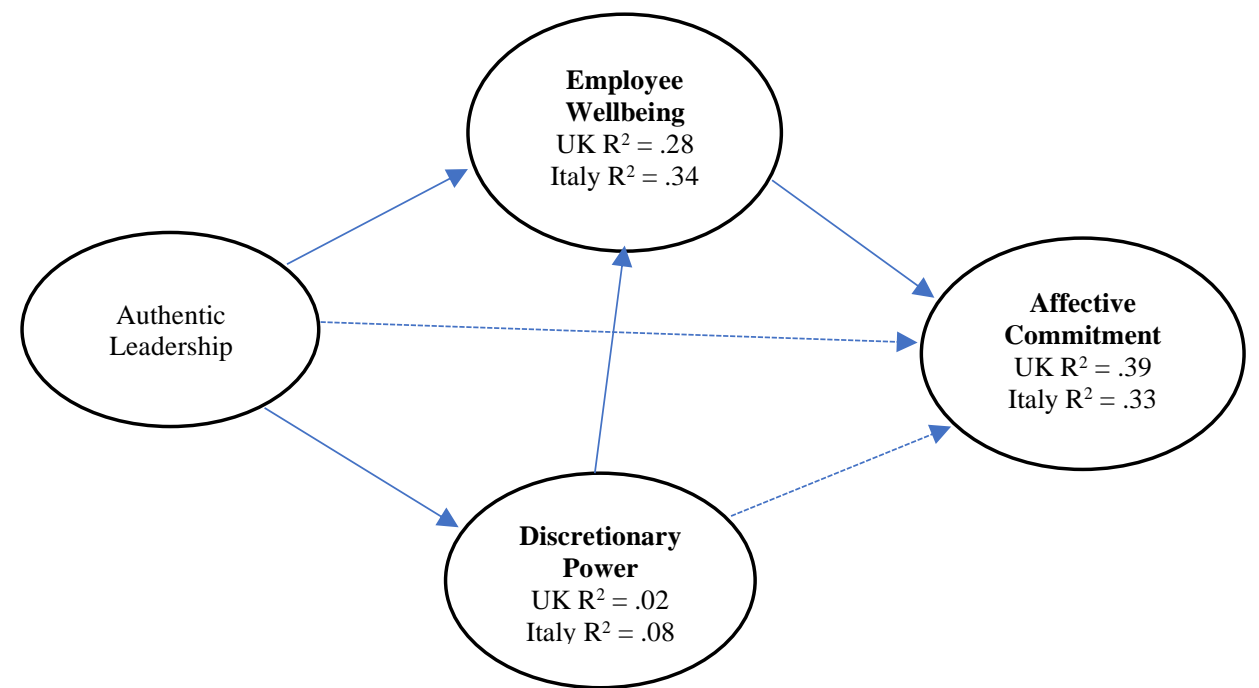

$P^{*<.05,} P^{* *<.01,} P^{* * *<.001, ~ I t a l y ~} n=203, U K n=228$, full blue lines indicate a significant path ${ }^{\wedge}$, dotted blue lines indicate a mediated path, direct and indirect beta values are displayed in table 3.

${ }^{\wedge}$ no significant path for UK from Authentic Leadership to Discretionary Power 
Table 1: Latent Mean comparison: UK to Italy

\begin{tabular}{llll}
\hline Construct & Italian Mean/SD & UK mean/SD & Estimate \\
\hline Authentic Leadership & $3.7(1)$ & $4(.95)$ & $.268^{* * *}$ \\
Wellbeing & $4.4(.7)$ & $4(.97)$ & $-.267^{* *}$ \\
Discretionary Power & $4.18(.9)$ & $4.2(.99)$ & .080 N.S. \\
Affective Commitment & $4.17(.9)$ & $3.85(1)$ & $-.203^{* *}$ \\
\hline
\end{tabular}

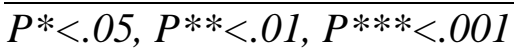

Table 2: SEM Direct and Indirect effects.

\begin{tabular}{|c|c|c|c|c|}
\hline Path & & Direct & Indirect & Evidence of \\
\hline \multirow[t]{2}{*}{$\mathrm{AL} \rightarrow \mathrm{DP}$} & UK & .13 N.S. & - & Path not significant \\
\hline & Italy & $.30 * *$ & - & Direct effect only \\
\hline \multirow[t]{2}{*}{$\mathrm{AL}->\mathrm{WB}$} & UK & $.29 * *$ & .05 N.S & Direct only \\
\hline & Italy & $.47 * *$ & $.07 * *$ & Partial Mediation through DP \\
\hline \multirow[t]{2}{*}{$\mathrm{AL} \rightarrow \mathrm{AC}$} & UK & -.05 N.S. & $.22 * *$ & Full mediation through DP and WB \\
\hline & Italy & -.01 N.S. & $.31 * *$ & Full mediation through DP and WB \\
\hline \multirow{2}{*}{$\mathrm{DP} \rightarrow \mathrm{WB}$} & UK & $.40^{* *}$ & - & Direct effect only \\
\hline & Italy & $.24 * *$ & - & Direct effect only \\
\hline \multirow[t]{2}{*}{$\mathrm{DP} \rightarrow \mathrm{AC}$} & UK & .05 N.S. & $.24 * *$ & Full mediation through WB \\
\hline & Italy & .14 N.S. & $.12 * *$ & Full mediation through WB \\
\hline \multirow[t]{2}{*}{$\mathrm{WB} \rightarrow \mathrm{AC}$} & UK & $.61 * *$ & - & Direct effect only \\
\hline & Italy & $.51 * *$ & - & Direct effect only \\
\hline \multirow[t]{2}{*}{ Gender $\rightarrow$ AC } & UK & $-.14 *$ & - & Direct effect only \\
\hline & Italy & .01 N.S. & - & Path not significant \\
\hline
\end{tabular}

